\title{
LA REPRESENTACIÓN TERRITORIAL: ¿REPRESENTACIÓN POLÍTICA O REPRESENTACIÓN DE INTERESES?
}

\author{
CLARO J. FERNÁNDEZ-CARNICERO \\ Letrado de las Cortes Generales
}

I. Ante la maraña de tópicos, ocurrencias arbitristas o abuso políticamente cínico del Derecho Comparado, no deja de ser arriesgado el intento de contribuir con una reflexión jurídica más, que no por independiente renuncia a ser útil, al hasta ahora frustrado debate sobre la reforma del Senado.

Antes que un análisis teórico del fundamento o sentido que entre nosotros justifica el bicameralismo, entiendo que se debe partir de un reconocimiento crítico del motivo real de la existencia de una segunda Cámara en el actual régimen constitucional español. Porque la Constitución de 1978 no trató de reanudar el tracto interrumpido con una tradición bicameral concluida con la II República y, obviamente, excluida durante las dictaduras de Primo de Rivera y Franco. En realidad, lo único que hizo nuestra Ley de leyes fue mantener, con algún retoque, el Senado preconstitucional de la Ley para la Reforma Política de 1977, cuya única razón de ser fue la de reubicar a parte de la clase política del régimen anterior. Sin duda este espíritu de órgano "nominal" (en el doble sentido de falto de realidad propia y de instrumento o cobertura de una nómina retributiva) ha marcado el perfil de la denominada, con más ironía que respeto, Alta Cámara ${ }^{1}$. Es hora, por tanto, de reconocer el lastre de esa marca o vicio de origen para, a partir de los principios y la estructura orgánica del marco jurídico-constitucional vigente, superarlo y hacer de la necesidad circunstancial virtud institucional.

II. El principio de territorialidad, constituyente de todo Estado, cualquiera que sea el régimen político que lo conforma, aparece recogido en el artículo $137 \mathrm{CE}$ al disponer que «el Estado se organiza territorialmente en municipios, en

1 Vid., por todos, la Tribuna, sobre "La Reforma del Senado", Real Academia de Ciencias Morales y Políticas, 1996.

UNED. Teoria y Realidad Constitucional, núm. 17, 2006, pp. 331-336. 
provincias y en las Comunidades Autónomas que se constituyan". A este reconocimiento de los sujetos que articulan la territorialidad estatal se suma el de la configuración de un régimen de autonomía, determinante de la funcionalidad de aquéllos, en estos términos: "todas estas entidades gozan de autonomía para la gestión de sus respectivos intereses". Ello no empece la singularidad jurídico-política del derecho a la autonomía, que el artículo 2 CE reconoce, no a las Comunidades Autónomas en cuanto tales (son corporaciones públicas de base territorial y de naturaleza política, según STC 25/1981) sino a las nacionalidades y regiones que son presupuesto consustancial e integrador de la Nación española. El concepto de autonomía tiene, en consecuencia, una dimensión funcional que lo hace inseparable de la identificación y gestión de un interés singular, al menos en términos relativos (por la dificultad de distinguirlo del interés general).

El territorio se configura, en consecuencia, como un espacio para la solidaridad intercomunitaria así como para la garantía equitativa "de un nivel mínimo en la prestación de los servicios públicos fundamentales", lo que conlleva la corrección estatal de los desequilibrios económicos interterritoriales (artículos 138 y 158 CE). Esta responsabilidad del Estado, como garante último del principio de solidaridad interterritorial, conlleva y reclama, en estricta lógica institucional, un órgano del máximo nivel político que contribuya a hacer realidad esos principios. Esta función nos acerca al sentido último y a la razón de ser del Senado en cuanto órgano estatal (y no mera conferencia de "embajadores" autonómicos) para la representación y defensa de los intereses territoriales y la cooperación entre las distintas Administraciones.

Con ese espíritu nos acercamos a la proposición enunciativa que el artículo 69.1 nos da del Senado como "Cámara de representación territorial". Es ésta una definición aparente, y por tanto insuficiente, que busca singularizar a la segunda Cámara, sin el compromiso de configurarla después como tal. En realidad, tendríamos que esperar hasta 1994, con la reforma del Reglamento del Senado, para introducir algunos elementos de territorialidad en la entonces creada Comisión General de Comunidades Autónomas. Su artículo 56 bis 2, tras incorporar la posibilidad de que el Gobierno pueda intervenir en sus sesiones, abre también la puerta a la participación de "los Consejos de Gobierno de las Comunidades Autónomas, representados por su Presidente o por el miembro del correspondiente órgano colegiado de gobierno designado para ello". Esta reforma apuntó hacia un horizonte institucional en el que la representación territorial empezaba a cobrar sentido en la palabra de los miembros de los gobiernos autonómicos, con lo que se dibujaba la posibilidad de un perfil distinto de una futura segunda Cámara.

Este perfil de representación de intereses territoriales a través de un órgano del Estado es perfectamente compatible con la dimensión política que se reconoce singularmente a las Comunidades Autónomas, a través de la elección y constitución de su Asamblea Legislativa respectiva. La distinción entre representación territorial y representación política, que debería definir el dualismo Senado/Congreso de los Diputados, priva de sentido a la actual presencia de 
los denominados senadores autonómicos, elegidos de conformidad con el artículo 69.5, por cuanto en ellos recae un doble mandato de representación política, directa e indirecta, y no propiamente un mandato de representación territorial.

En consecuencia, no cabe abordar la reforma del Senado sin una definición inequívoca del alcance de la representación territorial en cuanto diferente o distinta de la representación política. Es esta ambición de rigor conceptual la que nos permitirá configurar un órgano diverso y con vida propia.

En la Historia constitucional española no encontramos un fundamento claro para la definición singular de la representación territorial, por cuanto que la dimensión territorial de la circunscripción electoral ordinaria no suponía alteración en la naturaleza de la representación política asociada al mandato parlamentario.

Sin duda ha sido el modelo Bundesrat alemán el que más ha contribuido doctrinalmente a la definición de las segundas Cámaras de Estados políticamente descentralizados como Cámaras de representación de intereses territoriales, con el alcance reconocido en el artículo 50 de la Ley Fundamental de Bonn ( Por medio del Consejo Federal, los Estados cooperan en la legislación y administración de la Federación"). No estamos, por tanto, pensando en un modelo de representación corporativa de intereses, ajustada a lo que en la República de Weimar fue el Consejo Económico, con toda la ganga que después se añadiría desde el pensamiento político autoritario u orgánico; tampoco nos situamos en el ámbito de los Consejos económico-sociales, en el que cabe incluir al Consejo Económico y Social previsto en el artículo 131.2 CE. Cabría, en consecuencia, pensar en un tipo de bicameralismo en el que la perfección o imperfección no se redujera a la igualdad o desigualdad de los poderes de ambas Cámaras sino a la mejor o peor representación de la realidad jurídico-política del país respectivo.

Con ese perfil, el Senado debería integrar los intereses territoriales, fundamentalmente de las Comunidades Autónomas, pero también los de los municipios y las provincias, en congruencia con el referido artículo $137 \mathrm{CE}$. Todos ellos son intereses de naturaleza pública (y no privada como la que corresponde a los grupos de presión e interés o lobbies), lo que justifica el carácter complementario de la representación territorial respecto de la representación política, en la que, en realidad, el protagonismo corresponde a los partidos antes que a los ciudadanos. El interés general de éstos requiere, en consecuencia, la doble garantía que resulta de uno y otro tipo de representación. Por otra parte, al no encontrarnos propiamente ante un régimen federal, stricto sensu, la representación vinculada a los territorios no tiene dimensión política (que sólo se corresponde con un principio de soberanía o poder originario) sino de reconocimiento y defensa del interés singular de cada territorio del Estado.

En cuanto a las Comunidades Autónomas, su representación en la segunda Cámara debería encomendarse a los gobiernos respectivos, en cuanto gestores y defensores del interés territorial; ello sin perjuicio de arbitrar un criterio de proporcionalidad con la población de aquéllas (cabría fijar un mínimo de tres 
representantes y un máximo de ocho, a los que se vincularían las áreas competenciales reconocidas en el artículo $148 \mathrm{CE}$ y en los propios Estatutos). A esa representación, que conformaría la mayoría de la Cámara se sumarían dos representantes de los municipios de cada Comunidad Autónoma, elegidos por los Alcaldes, y un representante de las provincias, cuando éstas sean varias, elegido por los Presidentes de las respectivas Diputaciones Provinciales. Con ello se configuraría el Senado como Cámara indisoluble, como lo es la Cámara de los Lores del Reino Unido. También se mitigaría, con la representación municipal y provincial, la actual exacerbación del protagonismo de las Comunidades Autónomas y se racionalizarían, sin duda reduciéndose, los conflictos con el Estado central. Quedaría, siempre, en todo caso, la vía de formulación jurídicopolítica de un conflicto, a través de la interposición del correspondiente recurso de inconstitucionalidad, con la legitimación reconocida en el artículo $162 \mathrm{CE}$; o a través de la posibilidad que el Gobierno de la Nación tiene de impugnar ante el Tribunal Constitucional las disposiciones y resoluciones adoptadas por los órganos de las Comunidades Autónomas (artículo 161.2 CE).

Con esta nueva planta de la segunda Cámara no se pretende alteración del principio bicameral consagrado en el artículo 66.1 CE, lo que no obviaría la radical transformación de la posición del Senado que dejaría de ser un órgano formalmente colegislador, pasando a convertirse en un órgano de cooperación entre las distintas Corporaciones territoriales y de éstas, mediante sus iniciativas y propuestas, con la Cámara legisladora por excelencia, el Congreso de los Diputados. Por tanto, en congruencia con este perfil inequívocamente subordinado, el Senado conocería y dictaminaría, en primera lectura, todas las iniciativas legislativas remitidas por el Gobierno a las Cortes, o tomadas en consideración por el Congreso de los Diputados, sometiendo su Dictamen a la decisión de la Cámara de representación política (la que deriva de la elección por sufragio universal, libre, igual, directo y secreto), sin posibilidad alguna de veto (mitigados también en el marco de la actual reforma del federalismo alemán) o retorno a la Cámara de representación territorial. De la clarificación y separación de ambos tipos de representación, articulados a través de la Cámara respectiva, depende, en mi opinión, la consolidación misma del actual modelo de Estado autonómico que, insisto, no es propiamente federal por no reconocerse soberanía o poder político originario más que al pueblo español (artículo 1.2 CE), cuya representación política se sitúa, también exclusivamente, en el Congreso de los Diputados; lo que no empece el que el Senado participe, con su propia configuración subordinada a la primera Cámara (como en realidad ocurre también ahora), de la función institucional de representar al pueblo español (artículo 66.1 CE), en su doble dimensión real, ciudadana y territorial.

III. En el actual contexto de provisionalidad política, derivada del permanente anuncio de reforma en busca de "una auténtica Cámara de representación territorial" (que hasta ahí llega la expresión de lo pretendido), no debe confundirnos ese remedo o simulacro de Senado territorial que pretende ser la denominada Conferencia de Presidentes de Gobiernos, estatal y autonómicos. Su 
puesta en marcha en esta Legislatura no conduce sino a abundar en el convencimiento de la urgencia de una reforma de la segunda Cámara, con el objeto de favorecer la cooperación horizontal e intergubernamental entre las Comunidades Autónomas y, complementariamente, con los municipios y provincias.

En suma, en un Estado políticamente descentralizado como es el nuestro, debe configurarse la representación parlamentaria mediante la integración de la representación política (la que es parlamentaria por antonomasia, a la manera del Bundestag alemán) y la representación territorial, entendida como representación de intereses de los municipios, provincias y Comunidades Autónomas. La primera debería traducirse en un mandato representativo irrevocable, mientras que la segunda se ajustaría a la pauta del mandato imperativo, ajustada a la representación de intereses y sujeta a la eventualidad de revocación por la o las respectivas Administraciones territoriales representadas.

La dualidad expuesta no supone excluir del ámbito material de la representación política la defensa de intereses concretos de los ciudadanos. Lo único que subyace en el concepto de representación territorial es el reconocimiento de que, junto a esos intereses individuales o sociales asumidos por la representación política por antonomasia, la de la primera Cámara, existen también unos intereses territoriales singulares, que se vinculan a un tipo específico y distinto de representación, en la segunda Cámara.

Al Senado, en cuanto Cámara de representación de la diversidad de intereses territoriales concurrentes, amparados todos ellos por el principio de autonomía (artículo $137 \mathrm{CE}$ ), le corresponde institucionalizar la multilateralidad, connatural a esa pluralidad y concurrencia, con el espíritu de lo que Maritain denominó "democracia pluralista". Ello no excluye, como ya se ha advertido, la relación política bilateral de cada una de las Comunidades Autónomas con la Administración central en todo aquello que su singularidad justifique. La multilateralidad sería, por tanto, el contrapeso, que aportara deliberación pública, transparencia y equilibrio, frente a la inercia a acudir por principio, amparándose en la opacidad de la covachuela, a la relación bilateral. En realidad, con esta configuración de un Senado de nueva planta, se consagraría oficialmente el pacto que, hoy oficiosamente, suele buscarse entre el Gobierno central y las Comunidades Autónomas, a la hora de formular una iniciativa legislativa.

Finalmente, como primer corolario de estas reflexiones, debe reconocerse que la reforma del Senado no puede limitarse a los preceptos constitucionales que singularmente le contemplan. Por el contrario, la reforma de la segunda Cámara afecta sustancialmente, y de modo inescindible, a la configuración funcional de las Cortes Generales, que va más allá del estricto Título III de la Constitución (así, la intervención del Senado en la interpretación o reconocimiento del "interés general de España", en el supuesto de la actuación extraordinaria, —injerto artificioso de la "coerción federal" germánica_, prevista en el artículo $155 \mathrm{CE}$, debería corresponder, a mi juicio, una vez oída la Cámara territorial, al Congreso de los Diputados).

Como segundo corolario, cabe concluir en la necesidad de reformar la vigente Ley electoral, más allá de los obstáculos políticos que sin duda esto pre- 
senta, con el objeto de que en el Congreso de los Diputados, en cuanto Cámara de representación política, sólo participen aquellos partidos políticos con presencia, y concurrencia electoral, en todo el territorio nacional. Ello permite articular, en el Senado, conforme a un principio de asimetría democrática, la representación de los legítimos intereses territoriales, sujetos siempre a la decisión de la primera Cámara, en la que se integra y conforma la representación directa del pueblo español soberano.

Llegado a este punto, el jurista reconoce que ha franqueado en soledad, aunque con la Constitución en la mano, el umbral de la utopía, siempre necesaria en el horizonte abierto del debate político.

ABSTRACT. The Spanish Constitution has introduced a new model of state, politically decentralised, on the basis of the principle of territorial autonomy. In accordance with that ground, the second chamber, the Senate, is the House for the territorial representation (art. 69.1 of the Constitution). This specific role must lead to a clear differentiation with the first chamber, the Congress of Deputies, where lies the political representation, as the primary sign of sovereignity. The Senate must keep, in my opinion, the role of cooperating and integrating the territorial interests. of autonomous communities (at a governmental level), adding those from municipalities and provinces. 